\title{
Energy and substrate requirements of the placenta and fetus
}

\author{
BY WILLIAM W. HAY JR. \\ Division of Perinatal Medicine, University of Colorado School of Medicine, \\ 4200 East Ninth Avenue, Denver, Colorado 80262, USA
}

The exchange of nutrients between placenta and fetus involves three major mechanisms: (1) direct placental transfer of nutrients from the maternal to the fetal plasma, (2) placental metabolism and consumption of nutrients, (3) placental metabolism of mutrient substrates to alternate substrate forms. Additionally, placental size, architecture, developmental and pathological processes, and interaction with the fetus co-operate with transport and metabolic mechanisms to affect qualitatively and quantitatively placentalfetal nutrient exchange. Most of the findings and concepts that are reviewed reflect animal experimentation, given the paucity of in vivo physiological information from human studies for obvious technical and ethical reasons (Hay, 1989).

\section{EFFECT OF PLACENTAL SIZE}

The size of the fetus varies directly with the size of the placenta, although the fetal:placental weight ratio varies considerably among species and at different gestational ages. More definitively, experimental reduction in placental size produces smaller fetuses. Studies by Owens et al. (1987) for example, in which uterine carunculectomies were performed in non-pregnant sheep, thereby reducing placental surface implantation area and ultimate placental size, resulted in reduced fetal weight (control 3720 (SE 807) g, carunculectomy 2198 (SE 653) g) and placental glucose transfer to the fetus (control 18.4 (SE 2.7$) \mathrm{mg} / \mathrm{min}$, carunculectomy 11.1 (SE 1.2) $\mathrm{mg} / \mathrm{min}$ ). Both reductions were nearly proportionate to the decrease in placental cotyledonary number and weight. Similar observations of reduced placental size and fetal weight have been observed in humans in clinical situations in which vascular disorders or anatomical abnormalities of the uterus have precluded the normal growth of the placenta (Freese, 1972; Molteni et al. 1978).

In the study by Owens et al. (1987) it was also noticed that the fetal weight-specific glucose transfer rate from the placenta to the fetus did not change significantly (control 4.9 (SE 0.7 ) $\mathrm{mg} / \mathrm{min}$ per $\mathrm{kg}$, carunculectomy 5.1 (SE 2.0) $\mathrm{mg} / \mathrm{min}$ per $\mathrm{kg}$ ). However, the fetal:placental weight ratio was significantly greater in the carunculectomized animals than in the normal control group (carunculectomy 12.6 (SE 3.9), control 7.8 (SE 1.3)). Thus, it is likely that the remaining placental tissues in the carunculectomized group developed further structural or functional changes that allowed or promoted alternate nutrient transport. Consistent with this hypothesis is the observation in sheep that the placenta reaches maximum size and weight at mid-gestation, and then decreases in weight by $10-20 \%$ over the second half of gestation during which period, however, the fetus increases over tenfold in weight (Baur, 1977; Battaglia \& Meschia, 1986).

\section{OXYGEN CONSUMPTION AND $\mathrm{O}_{2}$ TRANSFER}

In pregnant sheep studied in vivo, the uteroplacental tissues consume nearly half the uterine $\mathrm{O}_{2}$ uptake (uteroplacenta 0.98 (SE 0.13) $\mathrm{mmol} / \mathrm{min}$, uterus $2 \cdot 16$ (sE $0 \cdot 15$ ) 
$\mathrm{mmol} / \mathrm{min}$ ); the balance is consumed by the fetus $(1.18$ (SE 0.06$) \mathrm{mmol} / \mathrm{min}$; Meschia et al. 1980). However, on a weight-specific basis $\mathrm{O}_{2}$ consumption by the uteroplacental tissues near term is four-fivefold greater than that of the fetus which itself has a metabolic rate approximately twice that of the adult. While these average values for uteroplacental $\mathrm{O}_{2}$ consumption are quite high, such rates are probably considerable under estimates of $\mathrm{O}_{2}$ utilization by placental cellular tissue alone. For example, based on an average placental weight near term of $330 \mathrm{~g}$ or approximately one-third of the uteroplacental mass and the estimate by Meschia et al. (1980) that at least $85 \%$ of uteroplacental metabolism is accounted for by the placenta alone, it can be estimated that placental cellular tissue would have a metabolic rate as high as that in brain, liver, kidney, and many tumour cells $\left(\mathrm{O}_{2}\right.$ consumption of about $1.5-2 \mu \mathrm{mol} / \mathrm{g}$ tissue per min).

Fetal $\mathrm{O}_{2}$ consumption increases over gestation on an absolute basis due to the rapidly increasing mass of fetal tissue (Molina et al. 1988). However, on a wet-weight-specific basis, fetal $\mathrm{O}_{2}$ consumption does not change while on a dry-weight-specific basis fetal $\mathrm{O}_{2}$ consumption decreases dramatically (Fig.1; Bell et al. 1987). This decrease in dry-weightspecific $\mathrm{O}_{2}$ consumption is probably due to at 'east two factors: (1) the decrease in fractional protein synthetic rate over the second half of gestation (Meier et al. 1981), (2) the decrease in the relative proportion of body-weight that is accounted for by the more highly metabolically active organs such as the brain, heart, liver and kidneys compared with the increase in relative body proportion of metabolically less active tissues, specifically skeletal muscle, fat and the bony skeleton (Waterlow et al. 1978; Battaglia \& Meschia, 1986).

\section{FETAL GLUCOSE METABOLISM}

The rate of fetal glucose utilization and the rate of fetal glucose oxidation depend directly on the simultaneous interaction of fetal plasma glucose and insulin concentrations and the supply of glucose to the fetal plasma glucose pool (Hay et al. 1988a). An example in near-term fetal sheep depicting the effect of glucose and insulin concentrations simultaneously on fetal glucose utilization is shown in Fig. 2. The proportion of glucose oxidized during short-term 3-4 h studies does not change significantly over the entire range of glucose utilized (Hay et al. 1989). Therefore, in the fetal lamb it appears that the principal effect of insulin is to increase the permeability of insulin-sensitive cells to glucose flux rather than to enhancing some intracellular aspect of glucose utilization (at least this is true for the whole animal on balance, whereas individual tissues may vary significantly in their responsiveness to insulin). Such a permissive role for insulin in the fetal lamb is somewhat different from that in adult humans in whom higher rates of glucose utilization are partitioned more into glucose storage (for example, fat and glycogen) than into oxidation. The same may be true of the human fetus which has the capacity to synthesize fat from glucose to a greater extent than the leaner fetal lamb. In the fetal lamb the disposition of non-oxidized glucose-carbon is less certain. Recent studies in our laboratory, however, have demonstrated significant contributions of fetal glucose- $\mathrm{C}$ to the formation of glycogen in the liver, heart, and lung, and a significant contribution to the $\mathrm{C}$ contained in amino acids and synthesized proteins (DiGiacomo et al. 1990).

At markedly reduced rates of glucose supply, fetal glucose utilization decreases proportionately (Hay et al. 1984, 1988a; Hay \& Meznarich, 1989). Under these short-term 


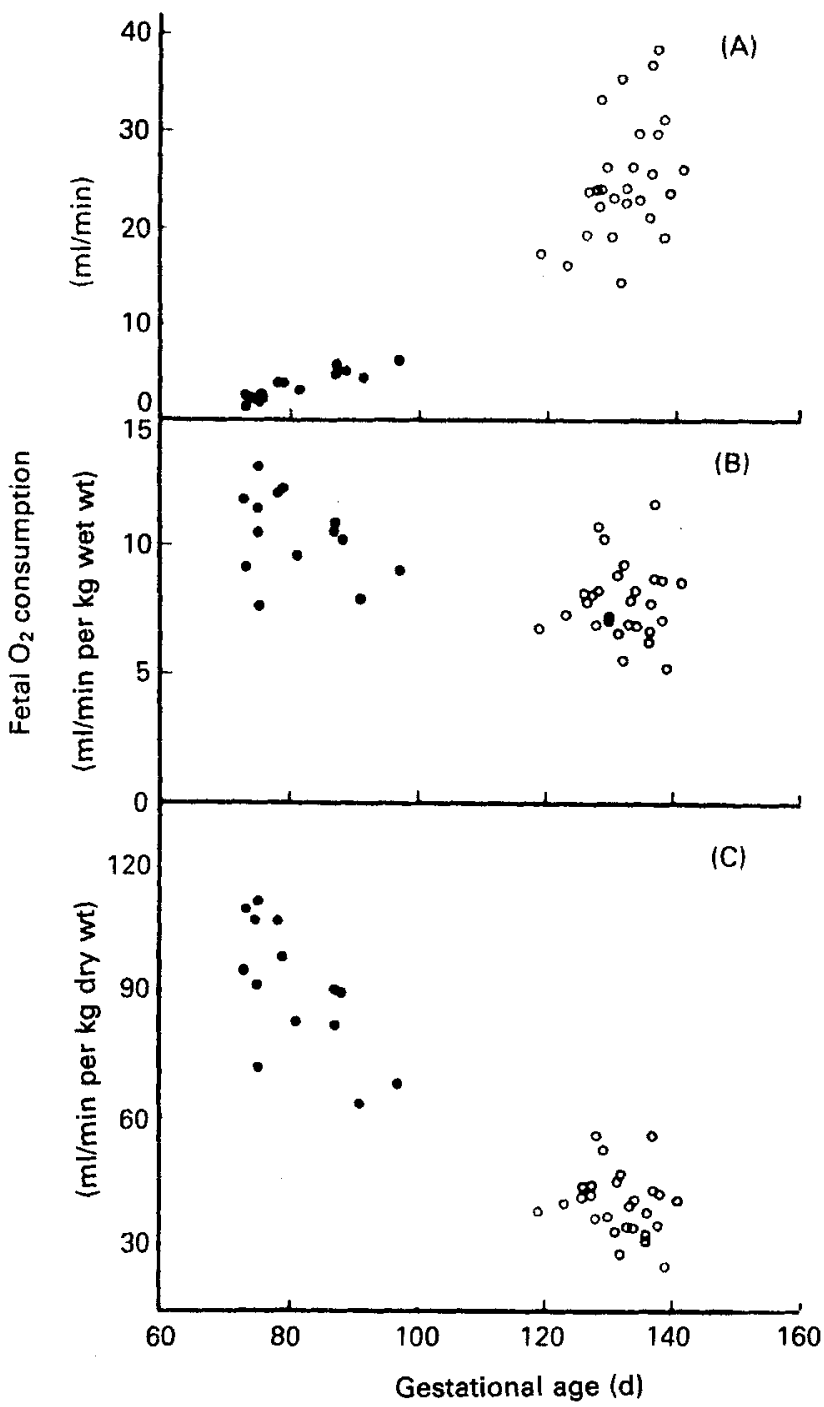

Fig. 1. Oxygen consumption $\left(\dot{V}_{\mathrm{O}_{2}}\right)$ in chronic, unstressed fetal sheep at different gestational ages plotted in absolute values (A), wet-weight-specific values (B), and dry-weight-specific values (C) at 73-97 d (O) and 119-141 d (O). The decrease in dry-weight-specific $\dot{V}_{O_{2}}$ with gestational age is consistent with a decreasing protein synthetic rate and a decrease in the relative proportion of body-weight contributed by high $\dot{V}_{\mathrm{O}_{2}}$ organs (brain, heart, liver, kidney, etc). Reproduced with permission of American Institute of Nutrition and the authors (Bell et al. 1987).

conditions fetal $\mathrm{O}_{2}$ consumption is sustained (Hay et al. 1989), suggesting active reciprocal oxidation of other substrates at least over the short term including, for example, glucose released from glycogen, lactate, fructose, amino acids and perhaps in the human fatty acids and ketoacids. Over longer periods of reduced glucose supply fetal $\mathrm{O}_{2}$ consumption tends to decrease somewhat, approaching a reduction of $25-30 \%$ 


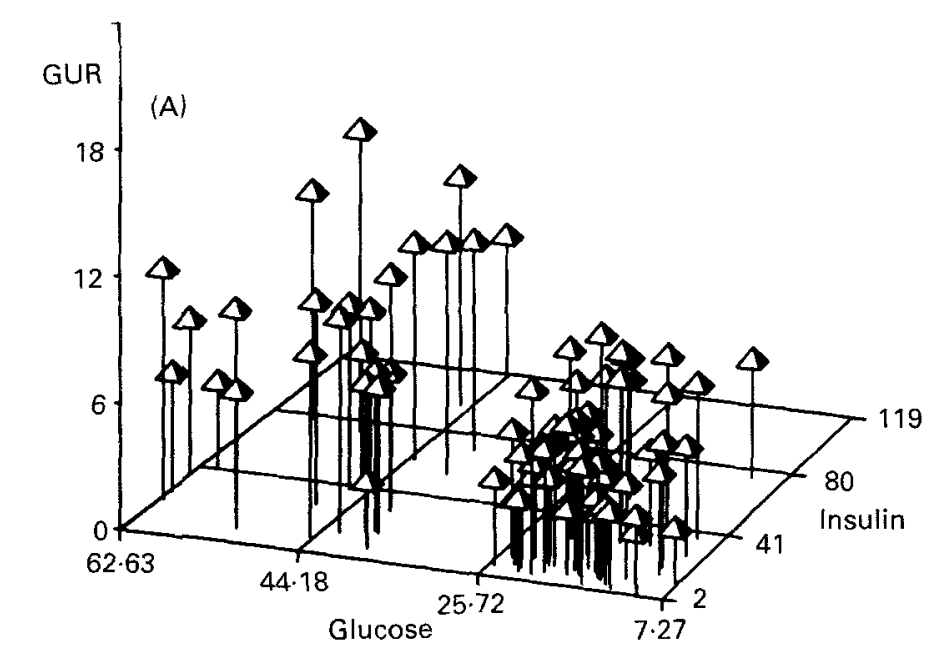

Pred GUR $\{B\rangle$

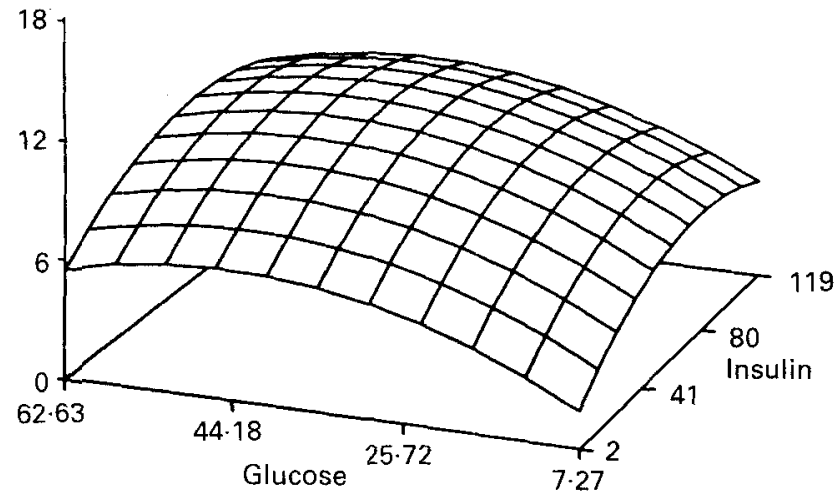

Fig. 2. Values from fetal sheep showing the additive effects of plasma glucose and insulin concentrations on fetal glucose utilization rate. (A) Three-dimensional plot of individual values of glucose utilization rate at different concentrations of glucose and insulin. (B) Predicted (Pred) three-dimensional glucose $x$ insulin surface from the values in (A) according to equation: GUR $=-0.322+(0.018$ (insulin) $)-(0.00319$ (glucose $\left.\left.)^{2}\right)-(0.000673 \text { (insulin })^{2}\right)$, where GUR is glucose utilization rate. Reprinted with permission of Pediatric Research and the authors (Hay et al. 1988a).

(DiGiacomo \& Hay, 1989). Because fetal growth decreases at the same time the decrease in fetal $\mathrm{O}_{2}$ consumption may represent a loss of fetal protein synthetic rate that is not completely counterbalanced by the $\mathrm{O}_{2}$ requirement necessary for fetal endogenous glucose production. The latter has been convincingly demonstrated in a variety of species now, but most particularly in the fetal lamb (DiGiacomo \& Hay, 1989). With sustained hypoglycaemia or fetal hypoinsulinaemia, or both, for more than several days glucose concentration tends to be sustained. In the case of selective hypoinsulinaemia, produced for example by fetal injection of streptozotocin (Hay et al. 1988b) or by pancreatectomy (Fowden \& Hay, 1988), glucose concentration actually increases. At the same time glucose utilization rate is maintained near normal in spite of up to $70-80 \%$ reduction in umbilical glucose supply. Infusion of glucose into these animals increases glucose 
utilization rate but does not appear to decrease the rate of endogenous glucose production. Only by the re-infusion of insulin to normal or higher-than-normal levels can this endogenous glucose production be diminished. Thus, it appears that a common denominator in these experiments is the effect of insulin on regulating fetal endogenous glucose production.

\section{PLACENTAL GLUCOSE TRANSFER AND CONSUMPTION}

Placental glucose transfer is directly related to the concentration of glucose in the maternal plasma, the uptake of glucose by the uterus and the maternal/fetal glucose concentration gradient (Hay et al. 1984, 1990; Hay \& Meznarich, 1989). Placental glucose transfer demonstrates concentration gradient-dependent, saturable, carriermediated transport (Widdas, 1952; Simmons et al. 1979). Placental glucose transporters have been identified in a variety of species on both the maternal-facing microvillus membrane of the trophoblast as well as the basal lateral fetal-facing membrane (Yudilevich et al. 1979; Johnson \& Smith, 1980, 1985; Ingerman et al. 1983). These transporters allow bidirectional transport of glucose across the placenta and the uptake of glucose by the trophoblast from both maternal and fetal glucose pools (Stacey et al. 1978). These transporters are of the insulin-independent variety and for the most part have similar molecular structure and genetic regulation as those that occur in the brain and on erythrocyte membranes (Kahn \& Flier, 1990).

Based on the Widdas (1952) model of Michaelis-Menton kinetic transport of glucose across the placenta, Simmons et al. (1979) used glucose clamp techniques in the maternal and fetal circulations of pregnant sheep and demonstrated that the relationship between placental glucose transport and the maternal-fetal arterial plasma glucose concentration difference across the placenta had a negative intercept; that is, placental glucose consumption contributed a major portion of the transplacental glucose gradient. These studies demonstrated, therefore, that uteroplacental glucose consumption is a hindrance to the transport of glucose into the umbilical circulation and accounts for the relative fetal hypoglycaemia. Without placental glucose consumption, for example, arterial glucose concentration in the fetal sheep would rise from the normal value of approximately $200 \mathrm{mg} / 1$ to approximately $450 \mathrm{mg} / 1$ (Simmons et al. 1979).

In these same and other studies glucose utilization by the placenta was shown to be a function of maternal glucose concentration. However, fetal glucose concentration co-varied with maternal glucose and it was not possible to separate the effects of the two variables. In more recent studies using glucose clamps that varied fetal glucose concentration independently of maternal glucose, uteroplacental glucose consumption was shown to be a function of fetal glucose concentration and virtually independent of maternal glucose concentration (Hay et al. 1990). These findings suggest that the fractional coefficient of uteroplacental glucose utilization from the fetal glucose pool is near unity. Similarly Simmons et al. (1979) showed that when the maternal and fetal glucose concentrations were identical approximately $80 \%$ of uteroplacental glucose consumption was derived from the fetal glucose pool. Thus, uteroplacental glucose metabolism is primarily 'placental', that is, by tissues that have direct access to glucose molecules carried by the umbilical circulation. Furthermore, the glucose transport capacity of the placental barrier is greater on its fetal than its maternal surface. Finally, placental glucose consumption is normally very high and if it remained at this high level 


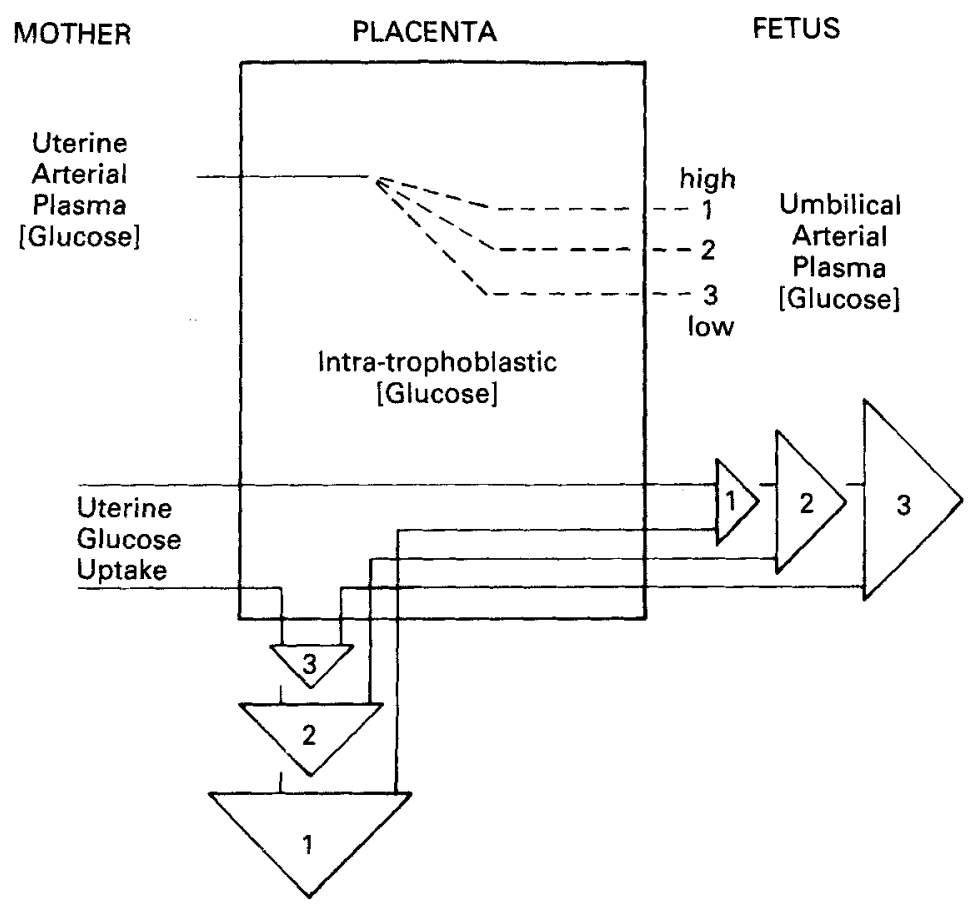

Fig. 3. Schematic effect of fetal glucose concentration on placental glucose transfer to the fetus and uteroplacental glucose consumption. A decrease in fetal glucose concentration relative to maternal glucose concentration promotes maternal-to-fetal glucose transfer at the expense of uteroplacental glucose consumption. These findings demonstrate a reciprocal relationship between placental glucose transfer and uteroplacental glucose consumption that is determined by the fetal glucose concentration.

when the mother becomes hypoglycaemic it would tend to block entirely the net transport of glucose into the umbilical circulation. Therefore, the decrease in placental glucose consumption that accompanies maternal hypoglycaemia is physiologically important for two reasons: (1) it decreases the demand of the conceptus on maternal glucose, and (2) it promotes the diversion of some maternal glucose from placental to fetal metabolism. Furthermore, to the extent that the fetus can regulate its own glucose concentration, for example, by endogenous glucose production, it can regulate not only glucose utilization by its own tissues but also those of the placenta, its major supply organ. Teleologically at least, it appears that this reciprocal relationship between glucose transfer to the fetus and placental glucose consumption that is regulated by fetal glucose concentration serves to protect both fetus and placenta without further taxing an already limited glucose supply from the mother (Fig. 3).

\section{GESTATIONAL MATURATION OF UTEROPLACENTAL GLUCOSE CONSUMPTION AND TRANSFER CAPACITY}

Over the second half of gestation in pregnant sheep, placental weight declines by about $20 \%$, but placental glucose transport capacity increases over eightfold (Molina et al. 1988). At least some of the increased glucose transport capacity (approximately $40 \%$ ) is 
the result of an increase in the transplacental glucose concentration gradient due to a progressive decrease in the fetal glucose concentration. Thus, the maturational changes in placental glucose transport capacity do not keep pace with the increase in glucose demand by the growing fetus. Based on the decreasing glucose concentration in the fetus, it is apparent that the glucose level on the growing fetus must decrease in order to balance glucose supply and demand. A decrease in fetal glucose level attains this balance via two separate mechanisms: (1) it increases the transplacental gradient thus increasing the entry rate of glucose into the fetus (which is necessary for the increasing fetal mass), and (2) it curbs fetal glucose demands by lowering the availability of glucose from fetal plasma to fetal tissues. For example, based on the findings described earlier which defined the response of fetal glucose utilization to changes in fetal blood glucose concentration (Hay et al. 1988a), it appears that as the fetus grows from mid-gestation to near term its glucose demands increase approximately fourteenfold (for example, from 1.5 to $21 \mathrm{mg} / \mathrm{min}$ ) which is much more than the $5 \cdot 5$-fold increase allowed by the increase in placental glucose transfer capacity at a constant value of transplacental glucose gradient. With no change in gradient the supply of glucose would increase only from 1.5 to $8.2 \mathrm{mg} / \mathrm{min}$. To match supply with demand, the fetus decreases its glucose concentration to a level that doubles the entry rate of glucose from the placenta (from 8.2 to $16.4 \mathrm{mg} / \mathrm{min}$ ) while at the same time it curbs glucose demand by approximately $20 \%$ (from 21 to $16.4 \mathrm{mg} / \mathrm{min}$ ) (Molina et al. 1991).

\section{PLACENTAL AMINO ACID TRANSFER AND FETAL AMINO ACID METABOLISM}

Placental amino acid uptake is an energy-dependent process (Yudilevich \& Sweiry, 1985). Inhibition of glycolysis and aerobic metabolism can suppress amino acid transport as demonstrated from both in vitro and in vivo studies (Smith, 1981; Illsley et al. 1984; Milley, 1988). Transporters require energy to concentrate the amino acids in the trophoblast intracellular matrix from which transport into the fetal plasma follows a decreasing concentration gradient (Hill \& Young, 1973; Eaton \& Yudilevich, 1981). Whether or not transport from the trophoblast intracellular matrix into the fetal plasma is energy dependent has not been determined.

Because of the relatively high rate of uterine blood flow, uterine uptake of amino acids from the maternal plasma has been difficult to quantify (Holzman et al. 1979a). Positive arterial-venous differences, however, have been measured for most amino acids with the exception of glutamate which is released by the placenta into the maternal circulation. Tracer studies have documented incorporation of amino acids into placental proteins and placental structural tissue (Carroll \& Young, 1982, 1983), but Fick principle approaches have been unable to demonstrate a net accumulation of amino acids at anytime during late gestation in experimental animals. Based on placental nitrogen content at term in the human placenta, however, placental growth over the entirety of gestation would require about $10.6 \mathrm{~g} \mathrm{~N}$ equivalent to about $66 \mathrm{~g}$ protein (Lemons, 1979).

Near term the placenta contains a large variety of enzymes that are capable of metabolizing amino acids through many metabolic pathways including gluconeogenesis, glycogenesis, protein synthesis, oxidation, ammoniagenesis, etc. (Edwards et al. 1977; Lemons, 1979). Amino acid flux through most of these pathways has been demonstrated in vitro but not in vivo, with the exception of ammoniagenesis which occurs in vivo in the 
sheep placenta and the human placenta (Holzman et al. 1977, 1979b). Other placental amino acid requirements include a small amount for oxidation, for the production of other amino acids by transamination pathways and an undetermined amount for the synthesis of secreted protein products (for example hormones such as human chorionic gonadotrophin, luteinizing hormone, placental lactogen and lipoproteins).

\section{AMINO ACID TRANSPORTERS ON THE PLACENTA}

At least three of the six common transport systems for amino acids have been found definitively in the human placenta (Enders et al. 1976). There is considerable overlap among the systems for different amino acids and one could expect quantitative changes in the balance of amino acids transported to the fetus produced by significant alterations in selected plasma amino acid concentrations. Such a theoretical possibility has not been tested in vivo, but may be a potentially important form of placental regulation of amino acid transport to the fetus. $\mathrm{Na}^{+} / \mathrm{K}^{+}$-transporting ATPase ( $E C$ 3.6.1.36) energizes the transport processes for sodium-dependent, Na-independent and hydrogen-dependent transport mechanisms (Balkovetz et al. 1986; Ganapathy et al. 1986). In vitro, amino acid transport systems appear to increase in response to a decrease in the amino acid concentrations of the incubation medium. This process can be blocked by inhibitors of protein synthesis (Smith et al. 1973). In vivo, one study in rats demonstrated maintenance of fetal amino acid concentrations in spite of prolonged hypoaminoacidaemia in the mother suggesting that a similar process of amino acid transporter-protein synthesis occurs in vivo in response to a decrease in amino acid concentrations (Domenech et al. 1986). These results take on added importance relative to observations by Cetin et al. (1988) who showed from umbilical blood vessel sampling findings in humans that the concentration of $\alpha$-amino- $\mathrm{N}$ was lower in maternal and fetal plasmas of growth-retarded infants. Placentas from these growth-retarded infants showed reduced transport of many amino acids but particularly the essential amino acids. Thus, the failure of the placenta to synthesize transporter proteins in response to hypoaminoacidaemia in the mother may be responsible for fetal growth retardation, an interesting but as yet untested hypothesis.

The reverse process also appears to occur, that is, trans-inhibition in which hyperaminoacidaemia suppresses amino acid transport. This appears to occur by competitive substrate binding on the 'trans' or opposite side of the uptake membrane, thereby limiting carrier mobility (Smith \& Depper, 1974). Trans-inhibition has been demonstrated in vitro but in vivo correlation is lacking. Additionally the placenta contains many hormone receptors (insulin, gonadotrophin, growth factors, somatomedin, $\beta$-adrenergics, cholinergics, opiates, etc.). For the most part there is no convincing evidence that placental amino acid transport is regulated by these hormones, although acetylcholine, perhaps by mediating changes in membrane potential, has been suggested as a potential regulator (Rowell \& Sastry, 1978, 1981). Many drugs and toxins have been implicated as inhibitors of amino acid transport. Mechanisms and clinical changes are not known for the most part. Ethanol and nicotine are common substances which have been shown in vitro, at least, to suppress amino acid transport across placental tissue (Henderson et al. 1981). Finally, many types of placental pathology exist (for example, hypertrophy, hypoplasia, infection, oedema, vascular malformations, calcium deposition, inflammatory changes, etc.) but there is no certain knowledge of their effect on amino acid transport by placental tissues. 


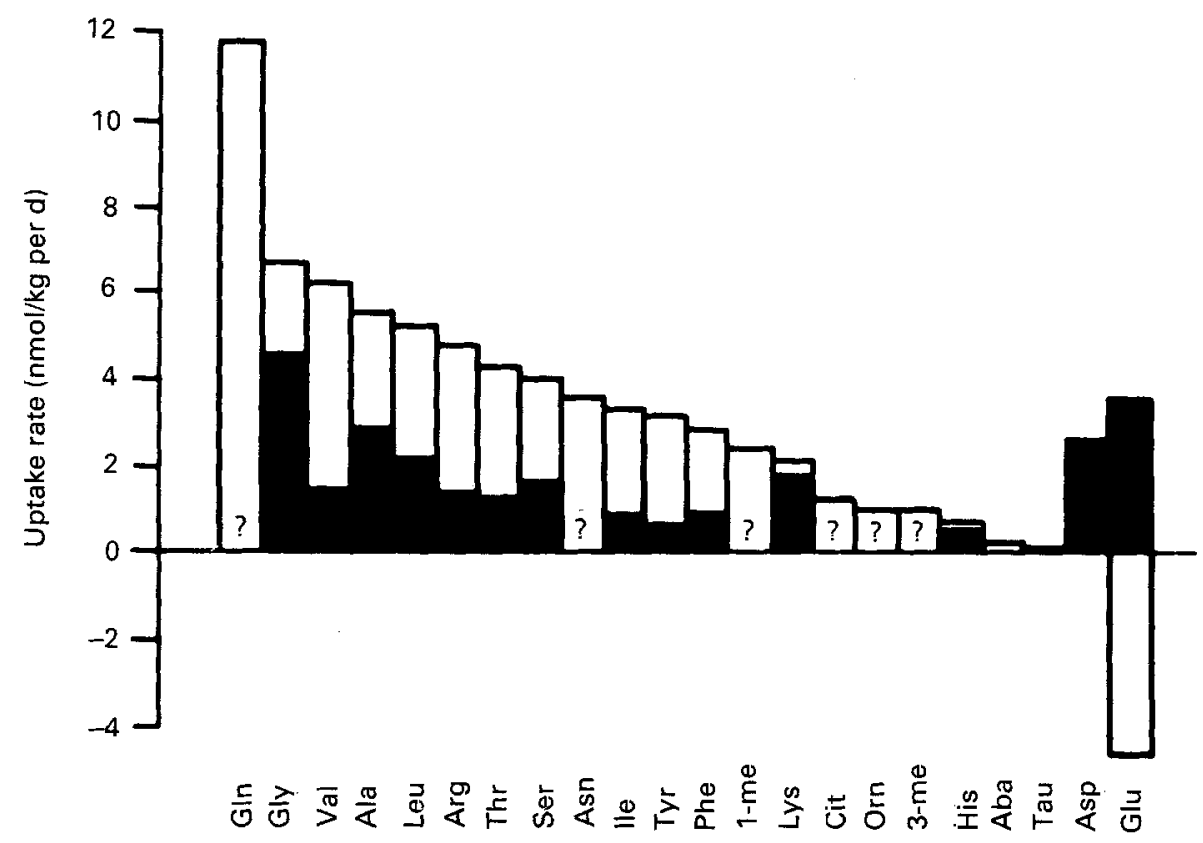

Fig. 4. Net umbilical uptake rates of selected amino acids in near-term fetal sheep (total, $\square$ ) exceeds net carcass accretion rates for most of the amino acids $(\boldsymbol{\square})$. The difference $(\square)$ represents a different metabolic rate, most likely oxidation, producing energy and carbon dioxide, and contributing to the high fetal urea excretion rate. Reproduced by copyright permission of American Society for Clinical Investigation and the authors (Lemons et al. 1976).

\section{FETAL AMINO ACID UPTAKE BY THE UMBILICAL CIRCULATION}

The uptake of amino acids by the umbilical circulation represents the exogenous or dietary supply of amino acids for fetal amino acid oxidation and protein synthesis. Quantification of this process has been accomplished in only one experimental animal, the fetal lamb. Fig. 4 shows the net uptake for each amino acid studied in the last $20 \%$ of gestation in fetal lambs (Lemons et al. 1976). Together the net amino acid uptake provides approximately $3-4 \mathrm{~g} \mathrm{C} / \mathrm{d}$ per $\mathrm{kg}$ fetal weight and $0.9 \mathrm{~g} \mathrm{~N} / \mathrm{d}$ (Marconi et al. 1989). The net $\mathrm{C}$ uptake provides approximately $50 \%$ of fetal $\mathrm{C}$ requirements for net accretion in carcass protein, glycogen, and fat, and utilization for oxidation that produces carbon dioxide. The $\mathrm{N}$ uptake is approximately $100 \%$ of the calculated requirement of about 1.0 g N/kg per d for carcass accretion (Battaglia \& Meschia, 1986).

As shown in Fig. 4 the net uptake of most of the amino acids exceeds their net accretion by considerable amounts. The excess uptake above carcass accretion requirements for the amino acids also implies that this portion of amino acid uptake is used for oxidation. Oxidation of amino acids in the fetus has been demonstrated in two ways. The fetus produces a large amount of urea (Gresham et al. 1972) and also produces C-labelled $\mathrm{CO}_{2}$ during fetal infusions of C-labelled amino acids (VanVeen et al. 1984, 1987). Several ${ }^{14} \mathrm{C}$-labelled amino acids have been infused into fetuses in vivo documenting ${ }^{14} \mathrm{CO}_{2}$ production, including, for example, leucine, lysine, serine, alanine, tyrosine and glycine. Oxidation rates have been calculated for leucine and lysine demonstrating that 


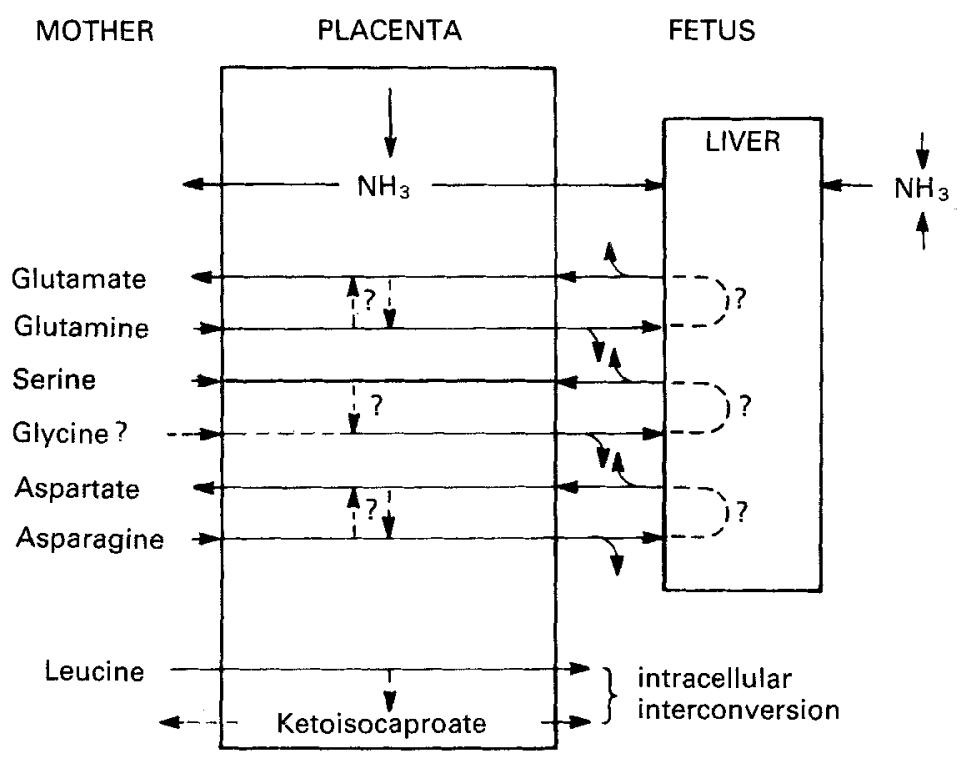

Fig. 5. Schematic of placental-fetal cycles resulting from protein metabolism in the placenta and fetus in late-gestation pregnant sheep. Adapted from findings of: Holzman et al. 1977; Battaglia \& Meschia, 1988; Marconi et al. 1989; Cetin et al. 1990.

the oxidation:disposal ratio was directly related to the excess of umbilical uptake above accretion and to the plasma concentration of the amino acid. Leucine oxidation at mid-gestation was at least as great as at term indicating also that amino acids may provide $\mathrm{C}$ for fetal oxidation metabolism over a large part of gestation.

\section{PLACENTAL-FETAL AMINO ACID CYCLING}

Several examples of fetal-placental interorgan cycling for selected amino acids have been demonstrated recently (Fig. 5; Marconi et al. 1989; Cetin et al. 1990). This is an important area for future research and demonstrates clearly that co-operation between the placenta and fetus is an important aspect of fetal metabolism. For example, the placenta actively produces ammonia which is delivered into both uterine and umbilical circulations (Holzman et al. 1977, 1979b). This is a normal process in mammalian metabolism during fetal life occurring in all species studied to date, perhaps essential to conserve $\mathrm{N}$ for the high rate of fetal protein synthesis. A proportion of the net umbilical ammonia uptake is extracted by fetal tissues, perhaps contributing to hepatic urea formation and to other specific metabolic pathways. However, the ammonia taken up by the liver, approximately $6.5 \mu \mathrm{mol} / \mathrm{min}$ in fetal lambs near term, is between two- and $1 \cdot 5$-fold that taken up by the umbilical circulation demonstrating that considerable fetal endogenous ammonia production exists. Additionally, a recent study in sheep by Marconi et al. (1989) showed that the hepatic amino acid: $\mathrm{O}_{2}$ quotient was significantly higher than the umbilical amino acid: $\mathrm{O}_{2}$ quotient $(0.63$ (SE 0.87 ) v. 0.13 (SE 0.03)) implying a high rate of amino acid utilization by the fetal liver.

Measurements of umbilical and hepatic concentrations of amino acids in the fetal 
sheep in these same studies (Marconi et al. 1989; Cetin et al. 1990) found reciprocal relationships between three sets of amino acids. Glutamine, glycine and to a lesser extent asparagine were taken up by the fetus from the placenta and by the liver from the umbilical vein, whereas their metabolically-related products, glutamate, serine and aspartate respectively, were produced by the fetal liver and taken up again by the placenta. A final example of placental-fetal cycling involves the relatively high concentrations and activities of branched-chain amino acid aminotransferases found in the placenta both of sheep and humans. Studies in sheep suggest that net placental uptake and transamination to the corresponding $\alpha$-keto acid can occur for leucine (Loy et al. 1990). The effect of these processes on placental-fetal amino acid and ammonia cycling on fetal metabolism and growth remains to be determined. Their very existence, however, implies a level of regulation in fetal-placental metabolism that is far more sophisticated than originally conceived. Limitation of any one of these processes by pathological changes in the placenta may impact negatively and significantly on normal fetal growth and development and presents an exciting challenge for future research.

\section{PLACENTAL LIPID TRANSFER AND FETAL LIPID METABOLISM}

Placentas of different species have markedly different permeabilities and transport capacities for fatty acids (Coleman, 1986). As a result the fat content of fetuses varies markedly among species in direct relation to placental lipid transport (Widdowson, 1974; Battaglia \& Meschia, 1986). For example, the human placenta transports lipid at a very rapid rate and produces the fattest of all newborns. In human infants at term, lipid stores account for approximately $18 \%$ of body fat. The guinea-pig placenta transports fat almost as well as the human placenta, producing a fetus at term with approximately $110 \mathrm{~g}$ fat $/ \mathrm{kg}$ body-weight. The rabbit fetus at term has approximately $70 \mathrm{~g}$ fat $/ \mathrm{kg}$ body-weight and the fetal lamb approximately $30 \mathrm{~g}$ fat $/ \mathrm{kg}$ body-weight. Fat deposition increases markedly in the second half of gestation in the human infant (Sparks et al. 1980). Whether this is due more to increased developmental capacity for fat synthesis or to increased fatty acid transport across the placenta is not known.

Net flux of fatty acids across the placenta can occur by at least three mechanisms (Coleman, 1986): (1) direct transfer by carrier-mediated transport, (2) synthesis within the placenta and subsequent release into the umbilical circulation, (3) hydrolysis of complex triacylglycerols, lipoproteins and phospholipids derived primarily from the maternal but also possibly from the fetal circulation. After entering into the placenta fatty acids may be used for glycerolipid synthesis, cholesterol esterification, membrane biosynthesis, direct transfer to the fetus, or for oxidation in the placenta providing energy (Szabo et al. 1973; Christie \& Noble, 1982; Coleman \& Haynes, 1987). Factors regulating the flux of lipid-C into and through these various pathways of transport metabolism are not known. At least one factor appears to be the maternal plasma free fatty acid concentration (Thomas et al. 1983). For example, placental triacylglycerol content increases in women who are fasting, who deliver preterm infants, or who have diabetes mellitus, all conditions in which maternal plasma free fatty acid concentrations are increased. Although most fatty acids appear to be transported by direct carriermediated mechanisms, some studies suggest that chain-altering metabolism in intratrophoblast peroxisomes may lead to a greater transfer of medium-chain fatty acids into the fetal circulation (Coleman \& Haynes, 1984). This would be advantageous to fetal 
lipid metabolism which is limited in its capacity for oxidation of long-chain fats because of relatively low carnitine concentrations.

Lipid metabolism in the fetus includes the incorporation of fatty acids into membranes as phospholipids, esterification into triacylglycerols and subsequent deposition in brown and white adipose tissue, and oxidation (Jones \& Rolph, 1985). In most species fetal hepatic and adipose tissue can actively synthesize fatty acids primarily from short-chain fatty acids such as acetate, from lactate and amino acids and to a lesser extent from glucose (Vernon et al. 1981). Regulation of fat synthesis in the fetus is not known but probably is at least dependent on the concentrations of these substrates. Developmental aspects of enzymes responsible for fat synthesis have not been well studied. Fatty acid oxidation also is highly variable among species and among studies. The latter probably represents to a large extent marked differences in fetal condition produced by different experimental mechanisms. In general the fetus contains relatively low levels of acetylCoA, carnitine palmityl-CoA synthetase, 3-hydroxyacyl-CoA dehydrogenase ( $E C$ 1.1.1.35), carnitine acyltransferase $(E C 2.3 .1 .7)$ and carnitine palmitoyltransferase ( $E C$ 2.3.1.21) (Bell \& Coleman, 1980). Furthermore, ketone production is generally low, probably due to relatively low levels of glucagon and, thus, relatively inactive hydroxymethylglutaryl-CoA synthase (EC 4.1.3.5) (Quant et al. 1990). In contrast oxidation of ketones may be quite rapid providing an alternative fuel during such conditions as maternal ketonaemia in the presence of hypoglycaemia.

\section{FETAL ENERGY SUPPLY $v$. AMINO ACID OXIDATION AND GROWTH}

As discussed earlier, glucose oxidation rates in fetal sheep can change by nearly twofold over the physiological range of fetal glucose and insulin concentration. In contrast, fetal $\mathrm{O}_{2}$ consumption or metabolic rate is relatively constant indicating that a reciprocal relationship must exist, at least over the short term, between glucose oxidation and that of other energy-producing substrates. Given the increase in the leucine oxidation: disposal ratio (Fig. 6) during sustained glucose deficiency, hypoglycaemia and hypoinsulinaemia, it appears that at least some amino acids can be diverted from protein synthesis and net protein accretion to protein catabolism and oxidation, either directly or via gluconeogenesis. Such observations suggest that fetal protein catabolism is regulated by non-protein energy supply and that certain amino acids released by protein catabolism can be oxidized directly to maintain fetal energy balance or may be metabolized also to glucose synthesis. Both of these processes would occur at the expense of fetal growth. At least two experimental models in which energy supply to the fetus is reduced by restricting glucose transfer from the placenta to the fetus result in fetal growth retardation (Hay et al. 1988a; DiGiacomo \& Hay, 1989). Similarly the fetus grows at a slower rate in animals that have primary hypoinsulinaemia and secondary hyperglycaemia which reduces the exogenous supply of glucose from the placenta (Fowden \& Hay, 1988). Furthermore, as discussed earlier, placental hindrance of glucose transport to the fetus over the second half of gestation induces a relative hypoglycaemia in the fetal plasma. Although this relative fetal hypoglycaemia increases the placental gradient for glucose transport, it also limits the transport of glucose from the plasma into fetal tissues and thereby may restrict fetal growth. Certainly, conditions in which fetal glycaemia is maintained at higher values, for example in infants of diabetic mothers, there appears to be an excessive rate of fetal growth and macrosomia. In these ways, placental regulation 


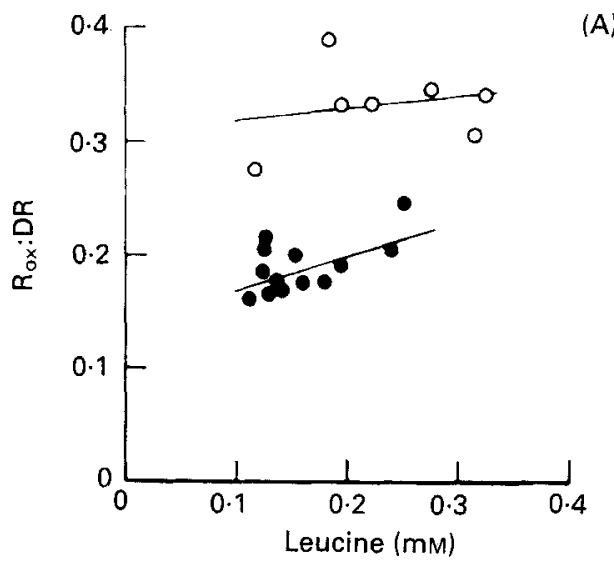

(A)

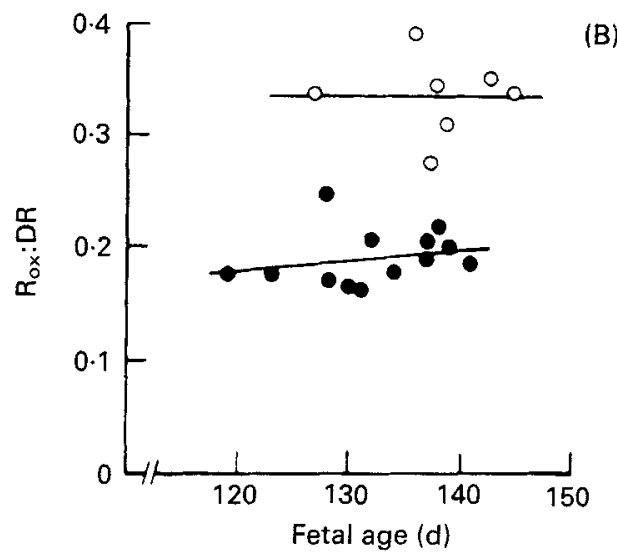

Fig. 6. With use of $\left[\mathrm{U}^{-14} \mathrm{C}\right]$ leucine tracer in fetal sheep, the leucine oxidation:disposal rate ratio (Rox:DR) nearly doubles with fasting, demonstrating a reciprocal relationship between amino acid oxidation and energy supply. Reproduced with permission of W. B. Saunders Co. and the authors (VanVeen et al. 1987). (O), Fasted; (৩), fed.

of fetal energy substrate supply can interact with fetal metabolism requirements to control fetal protein balance and growth as well as energy balance. Such interactions may be part of normal developmental processes and may be accelerated in certain clinical pathological conditions such as fetal growth retardation and fetal macrosomia.

The author acknowledges support by National Institutes of Health grants nos. DK35836, HD20761, and HD00781.

\section{REFERENCES}

Balkovetz, D. F., Leibach, F. H., Mahesh, V. B., Devoe, L. D., Cragoe, E. J. Jr \& Ganapathy, V. (1986). $\mathrm{Na}^{+}-\mathrm{H}^{+}$-exchanger of human placental brush-border membrane: identification and characterization. American Journal of Physiology 251, C852-C860.

Battaglia, F. C. \& Meschia, G. (1986). An Introduction to Fetal Physiology. Orlando: Academic Press Inc.

Battaglia, F. C. \& Meschia, G. (1988). Fetal nutrition. Annual Review of Nutrition 8, 43-61.

Baur, R. (1977). Morphometry of the placental exchange area. Advances in Anatomy, Embryology and Cell Biology 53, 5-65. 
Bell, A. W., Battaglia, F. C. \& Meschia, G. (1987). Relation between metabolic rate and body size in the ovine fetus. Journal of Nutrition 117, 1181-1186.

Bell, R. M. \& Coleman, R. A. (1980). Enzymes of glycerolipid synthesis in eukaryotes. Annual Review of Biochemistry 49, 459-487.

Carroll, M. J. \& Young, M. (1982). Mixed protein synthetic rate in the tissue of the isolated lobule of the human placenta. Journal of Physiology 332, $5 \mathrm{P}$.

Carroll, M. J. \& Young, M. (1983). The relationship between placental protein synthesis and transfer of amino acids. Biochemical Journal 210, 99-105.

Cetin, I., Marconi, A. M., Bozzetti, P., Sereni, L. P., Corbetta, C. M., Pardi, G. \& Battaglia, F. C. (1988). Umbilical amino acid concentrations in appropriate and small for gestational age infants: a biochemical difference present in utero. American Journal of Obstetrics and Gynecology 158, 120-126.

Cetin, I., Sparks, J. W., Quick, A. N. Jr, Marconi, A. M., Meschia, G., Battaglia, F. C. \& Fennessey, P. V. (1991). Glycine turnover and oxidation and hepatic serine synthesis from glycine in fetal lambs. American Journal of Physiology 260, E371-E378.

Christie, W. W. \& Noble, R. C. (1982). Fatty acid biosynthesis in sheep placenta and maternal and fetal adipose tissue. Biology of the Neonate 42, 79-86.

Coleman, R. A. (1986). Placental metabolism and transport of lipid. Federation Proceedings 45, 2519-2523.

Coleman, R. A. \& Haynes, E. B. (1984). Microsomal and lysosomal enzymes of triacylglycerol metabolism in rat placenta. Biochemical Journal 217, 391-397.

Coleman, R. A. \& Haynes, E. B. (1987). Synthesis and release of fatty acids by human trophoblast cells in culture. Journal of Lipid Research 28, 1335-1341.

DiGiacomo, J. E., Carter, B. S., Battaglia, F. C. \& Hay, W. W. Jr (1990). Distribution of nonoxidized glucose carbon in liver, carcass, and glycogen in the late gestation fetal lamb. Pediairic Research 27, Abstr 240, $42 \mathrm{~A}$.

DiGiacomo, J. E. \& Hay, W. W. Jr (1989). Regulation of placental glucose transfer and consumption by fetal glucose production. Pediatric Research 25, 429-434.

Domenech, M., Gruppuso, P. A., Nishino, V. T., Susa, J. B. \& Schwartz, R. (1986). Preserved fetal plasma amino acid concentrations in the presence of maternal hypoaminoacidemia. Pediatric Research 20 , $1071-1076$.

Eaton, B. M. \& Yudilevich, D. L. (1981). Uptake and asymmetric efflux of amino acids at maternal and fetal sides of placenta. American Journal of Physiology 241, C106-C112.

Edwards, E. M., Rattenbury, J. M., Varnam, G. C. E., Dhand, U. P., Jeacock, M. K. \& Shepherd, D. A. L. (1977). Enzyme activities in the sheep placenta during the last three months of pregnancy, Biochemica Biophysica Acta 497, 133-143.

Enders, R. H., Judd, R. M., Donohue, T. M. \& Smith, C. H. (1976). Placental amino acid uptake. III. Transport systems for neutral amino acids. American Journal of Physiology 230, 706-710.

Fowden, A. L. \& Hay, W. W. Jr (1988). The effects of pancreatectomy on the rates of glucose utilization, oxidation and production in the sheep fetus. Quarterly Journal of Experimental Physiology 73, $973-984$.

Freese, V. E. (1972). Vascular relations of placental exchange areas in primates and man. In Respiratory Gas Exchange and Blood Flow in the Placenta. DHEW Publication (NIH) no. 73-361, pp. 31-54 [L. D. Longo and H. Bartels, editors]. Washington, DC: US Department of Health, Education and Welfare.

Ganapathy, M. E., Leibach, F. H., Mahesh, V. B., Howard, J. C., Devoe, L. D. \& Ganapathy, V. (1986). Characterization of tryptophan transport in human placental brush-border membrane vesicles. Biochemical Journal 238, 201-208.

Gresham, E. L., James, E. J., Raye, J. R., Battaglia, F. C., Makowski, E. L. \& Meschia, G. (1972). Production and excretion of urea by the fetal lamb. Pediatrics 372-379.

Hay, W. W. Jr (1989). Placental control of fetal metabolism. In Fetal Growth, pp. 34-52 [F. Sharp, R. B. Fraser and R. D. G. Milner, editors]. London: Royal Society of Obstetricians and Gynaecologists.

Hay, W. W. Jr, DiGiacomo, J. E., Meznarich, H. K., Hirst, K. \& Zerbe, G. (1989). Effects of physiologic levels of glucose and insulin on glucose oxidation and oxygen metabolism in the fetal lamb. American Journal of Physiology 256, E704-E713.

Hay, W. W. Jr \& Meznarich, H. K. (1989). Effect of maternal glucose concentration on uteroplacental glucose consumption and transfer in pregnant sheep. Proceedings of Society for Experimental Biology and Medicine $190,63-69$.

Hay, W. W. Jr, Meznarich, H. K., DiGiacomo, J. E., Hirst, K. \& Zerbe, G. (1988a). Effects of insulin and glucose concentrations on glucose utilization in fetal sheep. Pediatric Research 23, 381-387.

Hay, W. W. Jr, Meznarich, H. K. \& Fowden, A. (1988b). Effect of streptozotocin on rates of ovine fetal glucose utilization, oxidation and production in the sheep fetus. Metabolism 38, 30-37. 
Hay, W. W. Jr, Molina, R., DiGiacomo, J. E. \& Meschia, G. (1990). Model of placental glucose consumption and glucose transfer. American Journal of Physiology 258, R569-R577.

Hay, W. W. Jr, Sparks, J. W., Wilkening, R. B., Battaglia, F. C. \& Meschia, G. (1984). Fetal glucose uptake and utilization as functions of maternal glucose concentration. American Journal of Physiology 246, E237-E242.

Henderson, G. I., Turner, D., Patwardhan, R. V., Lumeng, L., Hoyumpa, A. M. \& Schenker, S. (1981). Inhibition of placental valine uptake after acute and chronic maternal ethanol consumption. Journal of Pharmacology and Experimental Therapeutics 216, 465-472.

Hill, P. M. M. \& Young, M. (1973). Net placental transfer of free amino acids against varying concentrations. Physiology 235, 409-422.

Holzman, I. R., Lemons, J. A., Meschia, G. \& Battaglia, F. C. (1977). Ammonia production by the pregnant uterus. Proceedings of Society for Experimental Biology and Medicine 156, 27-30.

Holzman, I. R., Lemons, J. A., Meschia, G. \& Battaglia, F. C. (1979a). Uterine uptake of amino acids and glutamine-glutamate balance in the pregant ewe. Journal of Developmental Physiology 1, 137-149.

Holzman, I. R., Philipps, A. F. \& Battaglia, F. C. (1979b). Glucose metabolism, lactate and ammonia production by the human placenta in vitro. Pediatric Research 13, 117-120.

Illsley, N. P., Harmonde, J. P., Penfold, P., Bardsley, S. E., Coade, S. B., Stacey, T. E. \& Hytten, F. E. (1984). Mechanical and metabolic viability of a placental perfusion system in vitro under oxygenated and anoxic conditions. Placenta 5, 213-225.

Ingerman, R. L., Bissonette, J. M. \& Kock, P. L. (1983). Glucose-sensitive and -insensitive cytochalasin-B binding proteins from microvillous plasma membranes of human placenta. Identification of the $D$-glucose transporter. Biochemica Biophysica Acta 730, 57-63.

Johnson, L. W. \& Smith, C. H. (1980). Monosaccharide transport across microvillous membrane of human placenta. American Journal of Physiology 238, C160-C168.

Johnson, L. W. \& Smith, C. H. (1985). Glucose transport across the basal plasma membrane of human placental syncytiotrophoblast. Biochimica Biophysica Acta 815, 44-50.

Jones, C. T. \& Rolph, T. P. (1985). Metabolism during fetal life: a functional assessment of metabolic development. Physiological Reviews 65, 357-430.

Kahn, B. B. \& Flier, J. S. (1990). Regulation of glucase-transporter gene expression in vitro and in vivo. Diabetes Care 13, 548-564.

Lemons, J. A. (1979). Fetal-placental nitrogen metabolism. Seminars in Perinatology 3, 177-190.

Lemons, J. A., Adcock, E. W. III, Jones, M. D. Jr, Naughton, M. A., Meschia, G. \& Battaglia, F. C. (1976). Umbilical uptake of amino acids in the unstressed fetal lamb. Journal of Clinical Investigation 58, 1428-1434.

Loy, G. L., Quick, A. N. Jr, Teng, C., Hay, W. W. Jr \& Fennessey, P. V. (1990). Versatile stable isotope technique for the measurement of amino acids and keto acids. Comparison with radioactive isotope and its use in measuring in vivo disposal rates. Analytical Biochemistry 185, 1-9.

Marconi, A. M., Sparks, J. W., Battaglia, F. C. \& Meschia, G. (1989). A comparison of amino acid arteriovenous differences across the liver, hindlimb and placenta in the fetal lamb. American Journal of Physiology 258, 2508-2512.

Meier, P. R., Peterson, R. B., Bonds, D. R., Meschia, G. \& Battaglia, F. C. (1981). Rates of protein synthesis and turnover in fetal life. American Journal of Physiology 240, E320-E324.

Meschia, G., Battaglia, F. C., Hay, W. W. Jr \& Sparks, J. W. (1980). Utilization of substrates by the ovine placenta in vivo. Federation Proceedings 39, 245-249.

Milley, J. R. (1988). Uptake of exogenous substrates during hypoxia in fetal lambs. American Journal of Physiology 254, E572-E578.

Molina, R. D., Meschia, G., Battaglia, F. C. \& Hay, W. W. Jr (1991). Gestational maturation of placental glucose transfer capacity in sheep. American Journal of Physiology (In the Press).

Molteni, R. A., Stys, S. J. \& Battaglia, F. C. (1978). Relationship of fetal and placental weight in human beings: fetal/placental weight ratios at various gestational ages and birth weight distributions. Journal of Reproductive Medicine 21, 327-334.

Owens, J. A., Falconer, J. \& Robinson, J. S. (1987). Effect of restriction of placental growth on fetal and utero-placental metabolism. Journal of Developmental Physiology 9, 225-238.

Quant, P. A., Tubbs, P. K. \& Brand, M. D. (1990). Glucagon activates mitochondrial 3-hydroxy3 methylglutaryl-CoA synthase in vivo by decreasing the extent of succinylation of the enzyme. European Journal of Biochemistry 187, 169-174. 
Rowell, P. P. \& Sastry, B. V. R. (1978). The influence of cholinergic blockade on the uptake of alpha-aminoisobutyric acid by isolated human placental villi. Toxicology and Applied Pharmacology 45 , 79-93.

Rowell, P. P. \& Sastry, B. V. R. (1981). Human placental cholinergic system: depression of the uptake of alpha-aminoisobutyric acid in isolated human placental villi by choline acetyltransferase inhibitors. Journal of Pharmacology and Experimental Therapeutics 216, 232-238.

Simmons, M. A., Battaglia, F. C. \& Meschia, G. (1979). Placental transfer of glucose. Journal of Developmental Physiology 1, 227-243.

Smith, C. H. (1981). Incubation techniques and investigation of placental transport mechanisms in vitro. Placenta, Suppl. 2, 163-176.

Smith, C. H., Adcock, E. W. III, Teasdale, F., Meschia, G. \& Battaglia, F. C. (1973). Placental amino acid uptake: Tissue preparation, kinetics, and pre-incubation effect. American Journal of Physiology 224, 558-564.

Smith, C. H. \& Depper, R. (1974). Placental amino acid uptake. II. Tissue pre-incubation, fluid distribution and mechanisms of regulation. Pediatric Research 8, 697-703.

Sparks, J. W., Girand, J. \& Battaglia, F. C. (1980). An estimate of the caloric requirements of the human fetus. Biology of the Neonate 38, 113-119.

Stacey, T. E., Weedon, A. P., Haworth, C., Ward, R. H. T. \& Boyd, R. D. H. (1978). Fetomaternal transfer of glucose analogues by sheep placenta. American Journal of Physiology 234, E32-E37.

Szabo, A. J., De Lellis, R. \& Grimaldi, R. D. (1973). Triglyceride synthesis by the human placenta. I. Incorporation of labeled palmitate into placental triglycerides. American Journal of Obstetrics and Gynecology 115, 257-262.

Thomas, C. R., Locoy, C., St. Hillaire, R. J. \& Brunzell, J. D. (1983). Studies on the placental hydrolysis and transfer of lipids to the fetal guinea pig. In Fetal Nutrition, Metabolism and Immunology: Role of the Placenta, pp. 135-148 [R. K. Miller and H. A. Thiede, editors]. New York: Plenum Press.

VanVeen, L. C., Hay, W. W. Jr, Battaglia, F. C. \& Meschia, G. (1984). Fetal $\mathrm{CO}_{2}$ kinetics. Journal of Developmental Physiology 6, 359-365.

VanVeen, L. C., Teng, C., Hay, W. W. Jr, Meschia, G. \& Battaglia, F. C. (1987). Leucine disposal and oxidation rates in the fetal lamb. Metabolism 36, 48-53.

Vernon, R. G., Clegg, R. A. \& Flint, D. J. (1981). Metabolism of sheep adipose tissue during pregnancy and lactation. Adaptation and regulation. Biochemical Journal 200, 307-314.

Waterlow, J. C., Garlick, P. J. \& Millward, D. J. (1978). Protein Turnover in Mammalian Tissues and in the Whole Body, p. 541. Amsterdam: Elsevier/North-Holland Biomedical Press.

Widdas, W. F. (1952). Inability of diffusion to account for placental glucose transfer in the sheep and consideration of the kinetics of a possible carrier transfer. Journal of Physiology 118, 23-29.

Widdowson, E. M. (1974). Changes in body proportion and composition during growth. In Scientific Foundations of Pediatrics, pp. 44-55 [J. A. Davis and J. Dobbing, editors]. Philadelphia: W. B. Saunders Co.

Yudilevich, D. L., Eaton, B. M., Short, A. H. \& Leichtweiss, H. P. (1979). Glucose carriers at maternal and fetal sides of the trophoblast in guinea pig placenta. American Journal of Physiology 237, C205-C212.

Yudilevich, D. L. \& Sweiry, J. H. (1985). Transport of amino acids in the placenta. Biochimica Biophysica Acta 822, 169-201. 